\title{
IMPROVEMENT OF WEAR COMPONENT'S \\ PERFORMANCE BY UTILIZING ADVANCED MATERIALS AND NEW MANUFACTURING TECHNOLOGIES: CASTCON PROCESS FOR MINING APPLICATIONS
}

Quarterly Technical Progress Report

For the period starting April, 2002, ending June 30, 2002

Xiaodi Huang and Richard Gertsch

Michigan Technological University

1400 Townsend Drive

Houghton, MI 49931

August 27, 2002

\section{DE-FC26-01NT41055}

DISCLAIMER: This report was prepared as an account of work sponsored by an agency of the United States Government. Neither the United States Government nor any agency thereof, nor any of their employees, makes any warranty, express or implied, or assumes any legal liability or responsibility for the accuracy, completeness, or usefulness of any information, apparatus, product, or process disclosed, or represents that its use would not infringe privately owned rights. Reference herein to any specific commercial product, process, or service by trade name, trademark, manufacturer, or otherwise does not necessarily constitute or imply its endorsement, recommendation, or favoring by the United States Government or any agency thereof. The views and opinions of authors expressed herein do not necessarily state or reflect those of the United States Government or any agency thereof. 


\section{TABLE OF CONTENTS}

Abstract

Executive Summary

Experiment

Slow burnout

Warm isostatic pressing (WIP)

Thin plate burnout

Three passes of extrusion

Confinement burnout

Insert machining

Results

Slow burnout

Warm isostatic pressing

Thin plat burnout

Three passes of extrusion

Confinement burnout

Insert machining

Conclusions

\section{LIST OF FIGURES AND CHARTS}

CHART 1:

CHART 2:

CHART 3:

Figure 1a:

$1 b$ :

Figure 2a:

$2 b$ :

Figure 3a:

3b:

3c:

3d:

Figure 4a:

$4 b$ :

Figure 5a:

$5 b:$

Figure 6a:

$6 b:$

Figure 7a:

$7 b$ :
Slow burnout profile

Thin plate burnout profile

Confined burnout profile

Slow burnout

Slow burnout

WIP burnout

WIP burnout

Thin plate burnout

Thin plate burnout

Thin plate burnout

Thin plate burnout

Three passes of extrusion

Three passes of extrusion

Confinement burnout of a thin plate insert

Confinement burnout of a thin plate insert

Result of confinement burnout

Result of confinement burnout

Machined insert

Machined insert
3

4

4

6

6

6

6

7

7

7

7

7

7

8

8

8

8 


\begin{abstract}
The project has seen quite a bit of activity in this quarter, highlighted by the fabrication of a bit insert for field testing. In addition: 1) Several alternative process techniques were attempted to prevent bloating, cracking and delamination of FM material that occurs during binder burnout. The approaches included fabrication of FM material by three pass extrusion and warm isostatic pressing of green material, slow and confined burnouts as well as, burnout of thin plate instead of rod stock. Happily, a confined burnout followed by HIPing, produced FM button inserts without bloating or delamination. 2) Four rock bit inserts were produced from FM material and are ready for use on blast hole bits in the field. 3) Six of the project participants from Michigan Technological University, Advanced Ceramic Manufacturing, and The Robbins Group visited the Superior Rock Bit Company in Minnesota and planned the field test of FM inserts.
\end{abstract}

\title{
Experiments
}

Continuing discussion among the project participants settled on three possible reasons for the burnout problems: polymer constituents of the binder system, high polymer loading and the large size of the pieces, all of which contribute to binder removal problems. Selecting and optimizing the binder system would be a time consuming process involving a lot of experiments with no guarantee of success. It was decided to try other possible improvements and avoid changing the binder system at this time. Instead, adjustments to the binder removal process were made. These experiments are described below.

\section{$\underline{\text { Slow burnout }}$}

ACR tried a four-day vacuum burnout of a standard one-pass green FM rod with the following profile (Chart 1).

$25^{\circ} \mathrm{C}$ to $80^{\circ} \mathrm{C}$ in $3 \mathrm{hrs}$, $80^{\circ} \mathrm{C}$ to $175^{\circ} \mathrm{C}$ in $16 \mathrm{hrs}$, hold at $175^{\circ} \mathrm{C}$ for $8 \mathrm{hrs}$, $175^{\circ} \mathrm{C}$ to $300^{\circ} \mathrm{C}$ in $12 \mathrm{hrs}$, hold at $300^{\circ} \mathrm{C}$ for $6 \mathrm{hrs}$, $300^{\circ} \mathrm{C}$ to $350^{\circ} \mathrm{C}$ in $6 \mathrm{hrs}$, hold at $350^{\circ} \mathrm{C}$ for $6 \mathrm{hrs}$, $350^{\circ} \mathrm{C}$ to $400^{\circ} \mathrm{C}$ in $12 \mathrm{hrs}$, $400^{\circ} \mathrm{C}$ to $600^{\circ} \mathrm{C}$ in $12 \mathrm{hrs}$, hold at $600^{\circ} \mathrm{C}$ for $6 \mathrm{hrs}$, and a Nitrogen gas backfilled cool-down. 


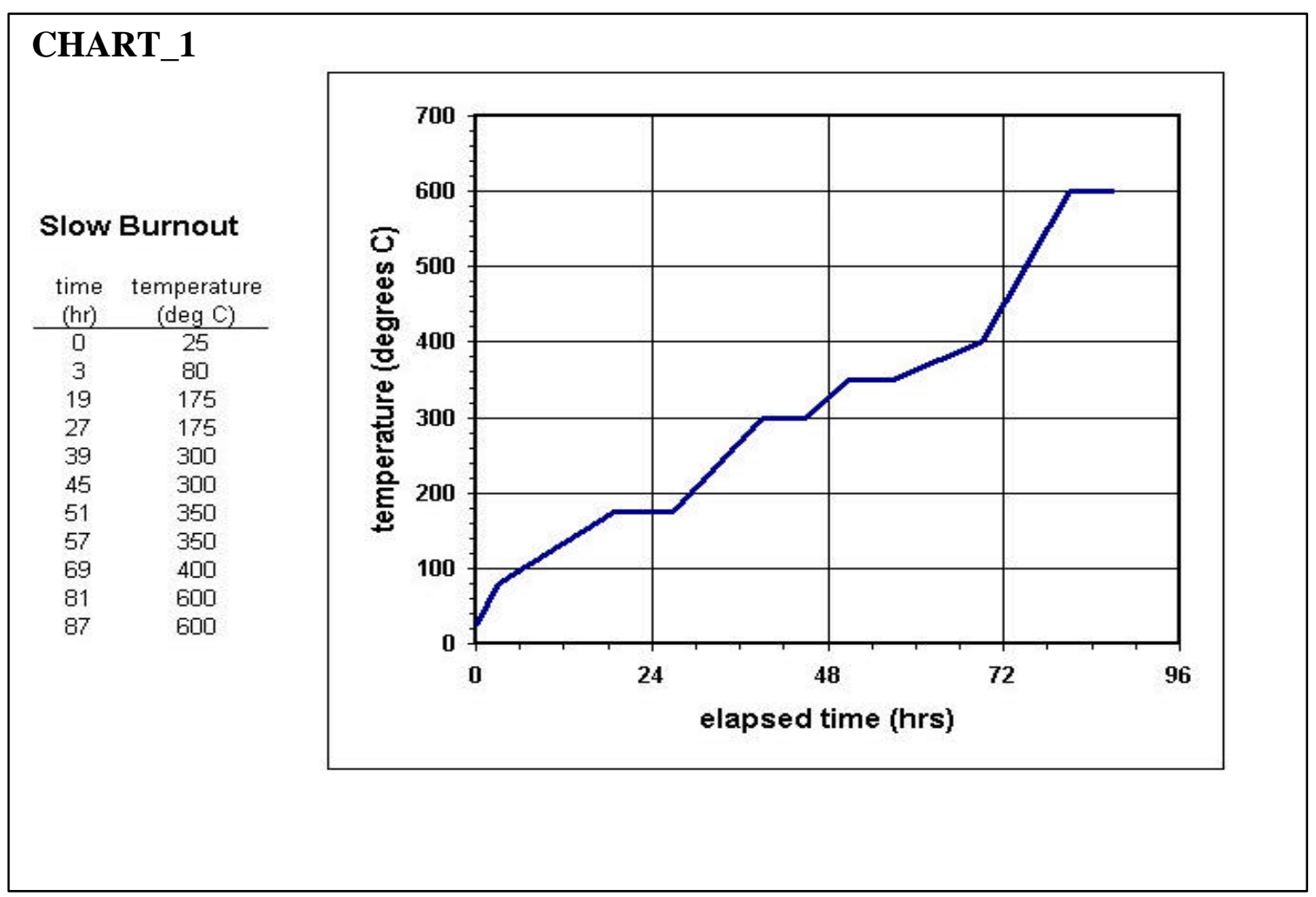

$\underline{\text { Warm isostatic pressing (WIP) }}$

Currently, ACR produces the FM green rods using two extrusion passes, followed by unidirectional warm pressing in a cylindrical die. It was thought that the unidirectional pressing may not provide sufficient transverse force (confinement) to ensure proper bonding between the fibers. ACR suggested the addition of warm isostatic pressing (WIP) after, unidirectional pressing. A green FM rod was WIPed at 100 psi and $140^{\circ} \mathrm{C}$ and sent to MTU for de-binding and sintering.

Thin plate burnout

A thin FM plate is needed as an insert for the disc cutters. It was believed that the thin plate could be less prone to burnout problems. Accordingly, a green FM plate of 3" x 2" x 0.5 " was produced by ACR. MTU cut and sliced it into four pieces of 3" x 0.98 " $\mathrm{x}$ 0.22 " each. Two of the pieces were burned out and sintered in a vacuum using the profile below (Chart 2).

0.1 degree per minute to $200^{\circ} \mathrm{C}$,

one hour soak at $200^{\circ} \mathrm{C}$,

0.5 degree per minute from 200 to $300^{\circ} \mathrm{C}$,

0.1 degree per minute from 300 to $400^{\circ} \mathrm{C}$,

0.5 degree per minute from 400 to $500^{\circ} \mathrm{C}$,

one hour soak at $500^{\circ} \mathrm{C}$,

degree per minute from 500 to $1100^{\circ} \mathrm{C}$, and one hour soak at $1100^{\circ} \mathrm{C}$. 


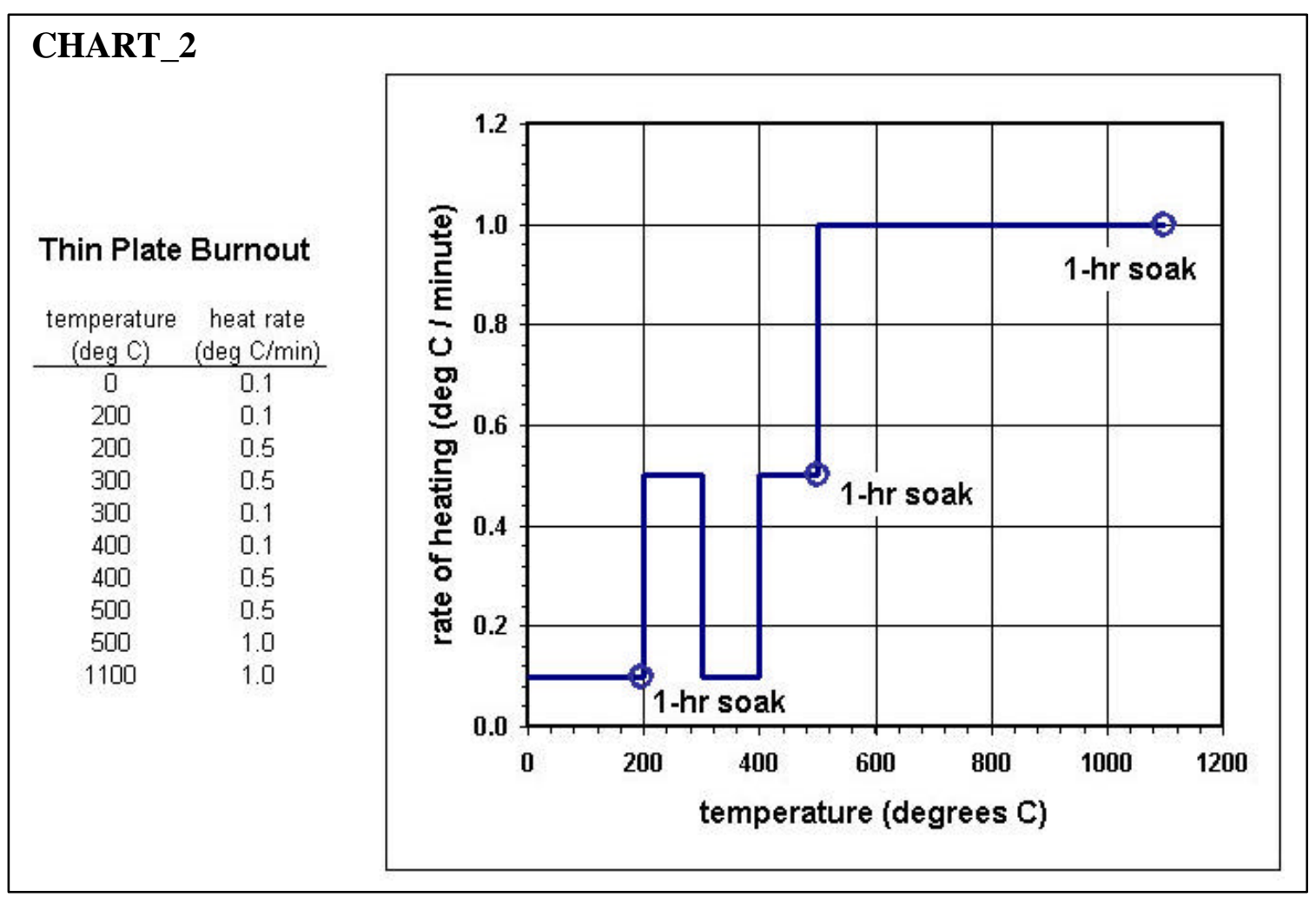

One piece was laid on a flat graphite plate and another was laid on a ceramic grill with hopes of improving vapor escape. The third piece was burned and sintered in a steel container filled with sand (confined burnout). The fourth piece was reserved for future experiments.

\section{$\underline{\text { Three extrusion passes }}$}

Unidirectional warm pressing may not create sufficient relative pressure between adjacent fiber bundles to bond them together resulting in delamination during burnout. It was thought that a third pass extrusion would provide better lamination due to increased pressure at the point of reduction. Typical extrusion has a reduction ratio of 10:1. Third pass attempt had a reduction ratio of 1.5:1. Therefore, we attempted a third pass extrusion technique. A green FM rod was produced by ACR. MTU performed a binder burnout (BBO) on this rod in a vacuum using the same profile as the above thin plate burnout. 


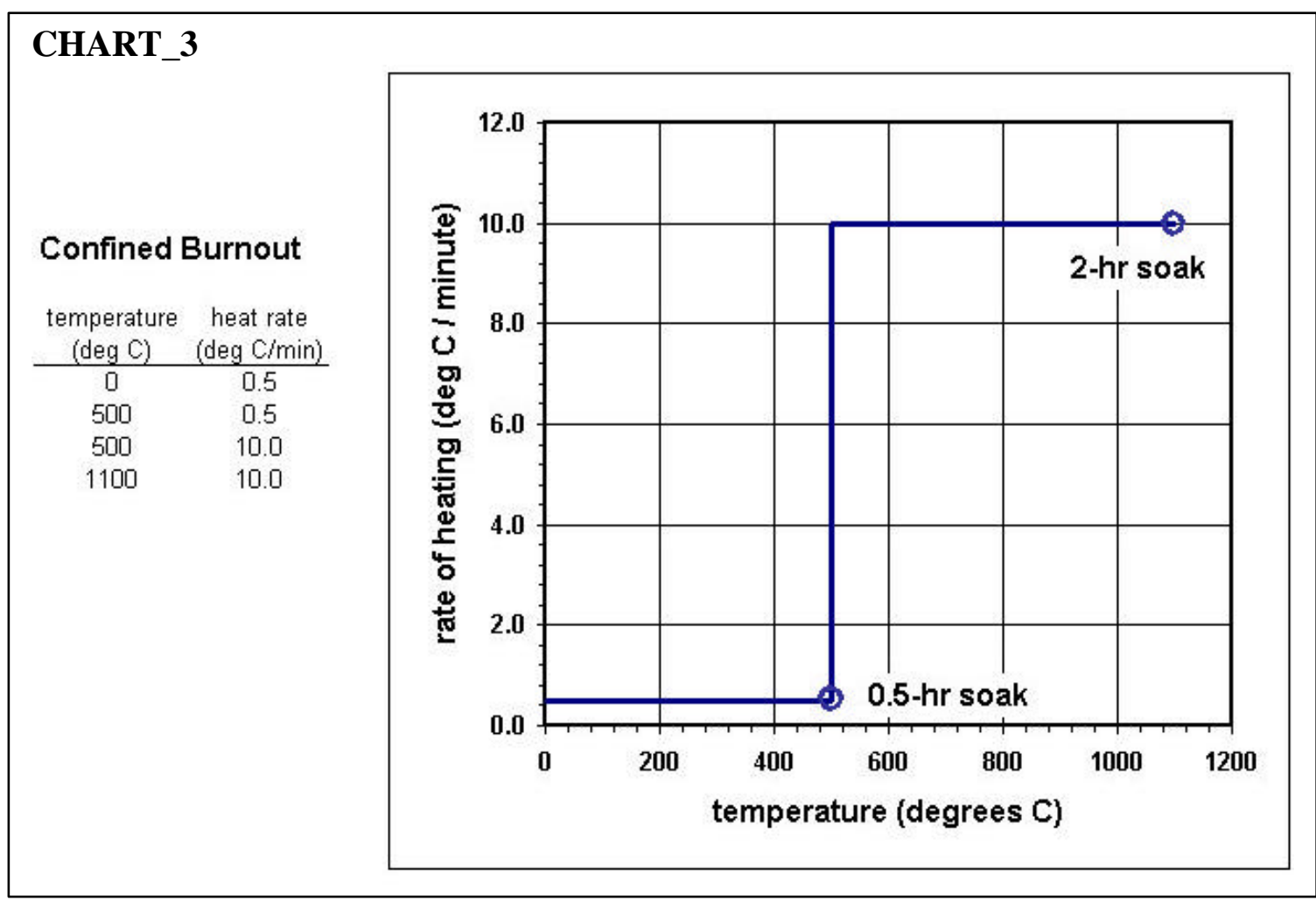

\section{Confined burnout}

Bloating and delaminating always occurred to varying extents during the burnout of the FM pieces, so perhaps providing confinement during burnout would prevent such happening. MTU inserted a green FM piece (the third piece cut from the thin plate discussed above) into a steel container, surrounded it with silica sand, and covered the container with a lid. The entire container was heated in a vacuum furnace using the following profile (Chart 3).

$0.5^{\circ} \mathrm{C}$ per minute to $500^{\circ} \mathrm{C}$ 30 minutes soak at $500^{\circ} \mathrm{C}$, $10^{\circ} \mathrm{C}$ per minute to $1100^{\circ} \mathrm{C}$, two-hour soak at $1100^{\circ} \mathrm{C}$, and furnace cool.

\section{$\underline{\text { Insert machining }}$}

Four HIPed insert blanks were sent to TRG, who made arrangements for final grinding by a ceramic machining company in central Oregon to produce inserts matching the shape of the standard TC inserts currently used by Superior Rock Bit. 


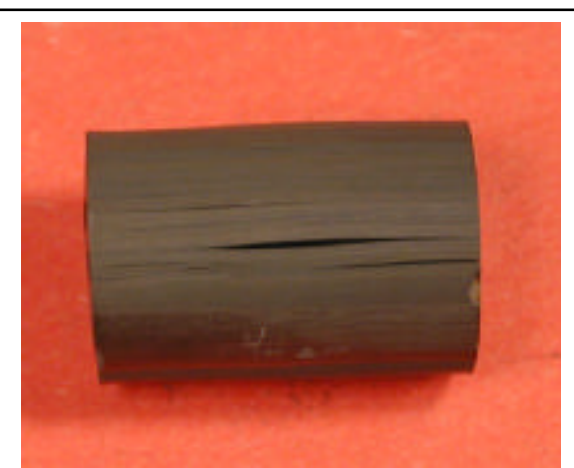

Figure 1a

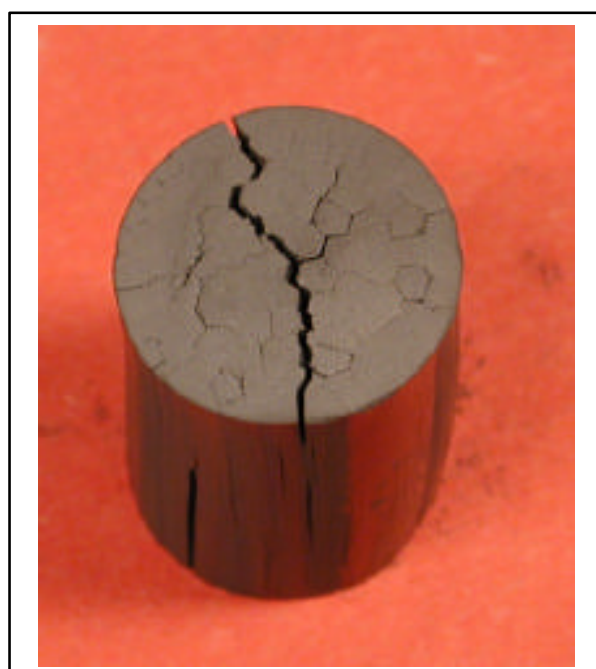

Figure 1b

\section{Results}

\section{$\underline{\text { Slow burnout }}$}

Figure 1a and $1 \mathrm{~b}$ show the result of the slow burnout of a cylindrical FM part $(\mathrm{OD}=$ 0.875 ", $\mathrm{L}=$ ?"). The diameter of the part grew by $0.17 \%$ during binder burnout. The height also grew by $4.5 \%$. From the pictures we see this "bloating" and that the part is no longer a right cylinder and tends to lean. The surface is smooth, no pimples, and no significant signs of out-gassing (gas entrapment) leading to bursting. (Out gassing defects (Fig 2a) look distinctly different from the delams seen on this part.) There are obvious signs of fiber delamination around fiber boundaries that may be a direct result of the stress created as the sample bloated causing the fiber separation.

\section{$\underline{\text { Warm isostatic pressing }}$}

Figure $2 \mathrm{a}$ and $2 \mathrm{~b}$ show the results of the WIP burnout. No obvious improvement.

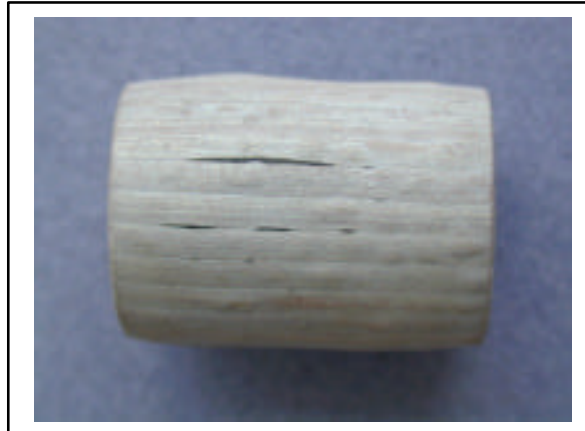

Figure 2a

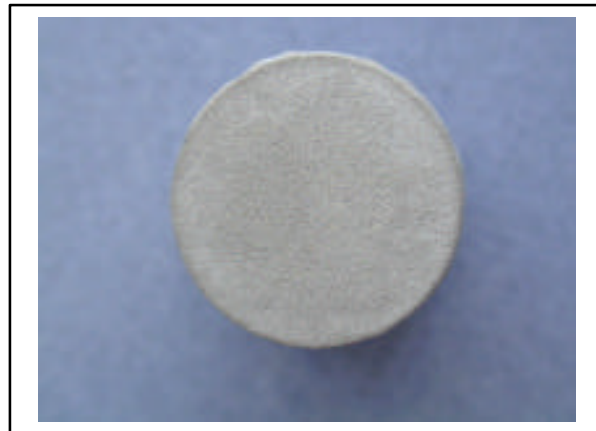

Figure $2 b$ 


\section{Thin plate burnout}

Figure $3 \mathrm{a}$ and $3 \mathrm{~b}$ show the burnout result of a thin plate laid on a flat graphite surface. Severe bloating, cracking and warping can be seen. Figures $3 \mathrm{c}$ and $3 \mathrm{~d}$ show the result when the thin plate burnout conducted on a ceramic grill. Severe bloating, cracking and warping still occurred.

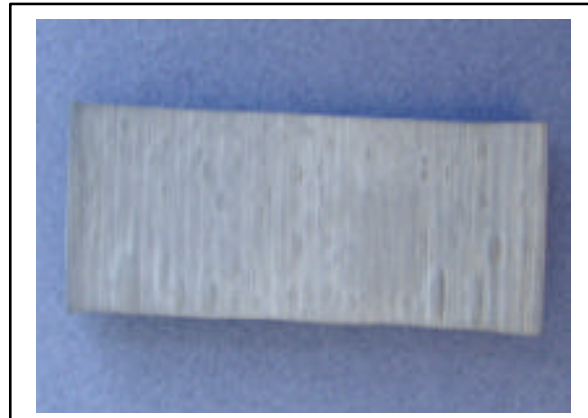

Figure $3 \mathrm{a}$

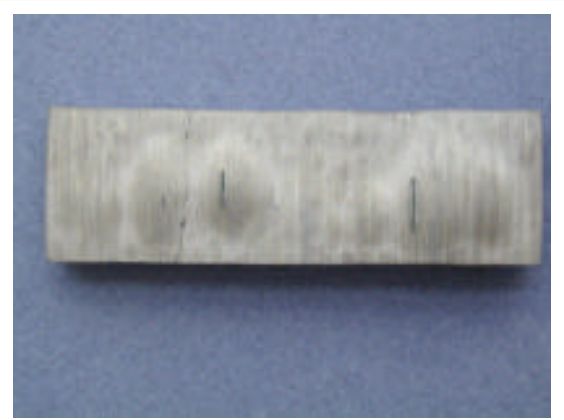

Figure 3c

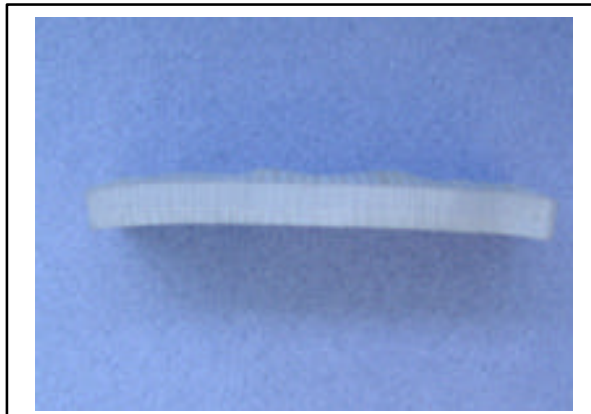

Figure $3 b$

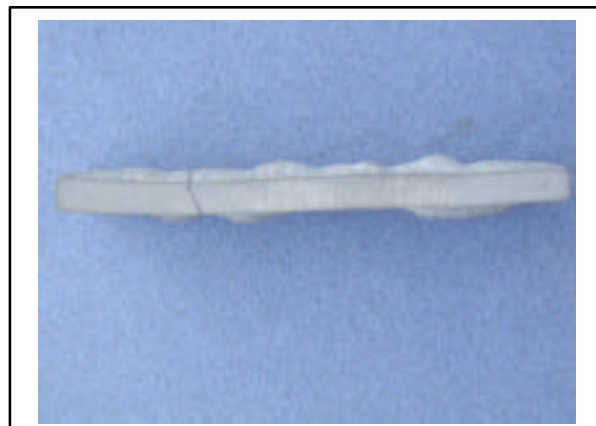

Figure 3d

\section{Three extrusion passes}

Figure $4 \mathrm{a}$ and $4 \mathrm{~b}$ show the burnout result of a green FM insert produced by third pass extrusion. No significant improvement can be seen.

\section{Confined burnout}

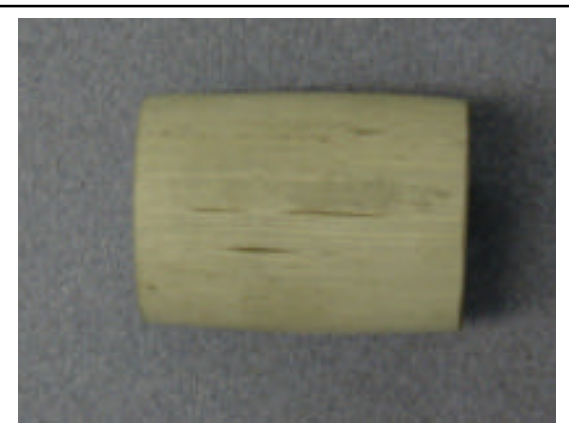

Figure $4 \mathrm{a}$

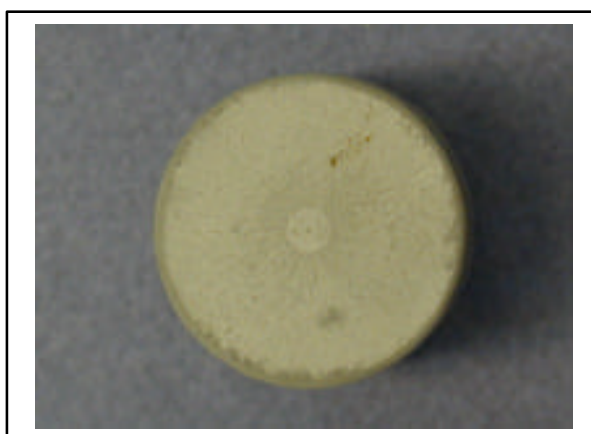

Figure $4 b$ 
Figures $5 \mathrm{a}$ and $5 \mathrm{~b}$ show the result of confinement burnout of a thin plate insert. The insert has no warping, no bloating, but many big cracks. The cracks seem different from previous burnout cracks and could possibly be caused by restricted sintering. Meaning that the surrounding silica sand mechanically blocked shrinkage of the thin plate during sintering.
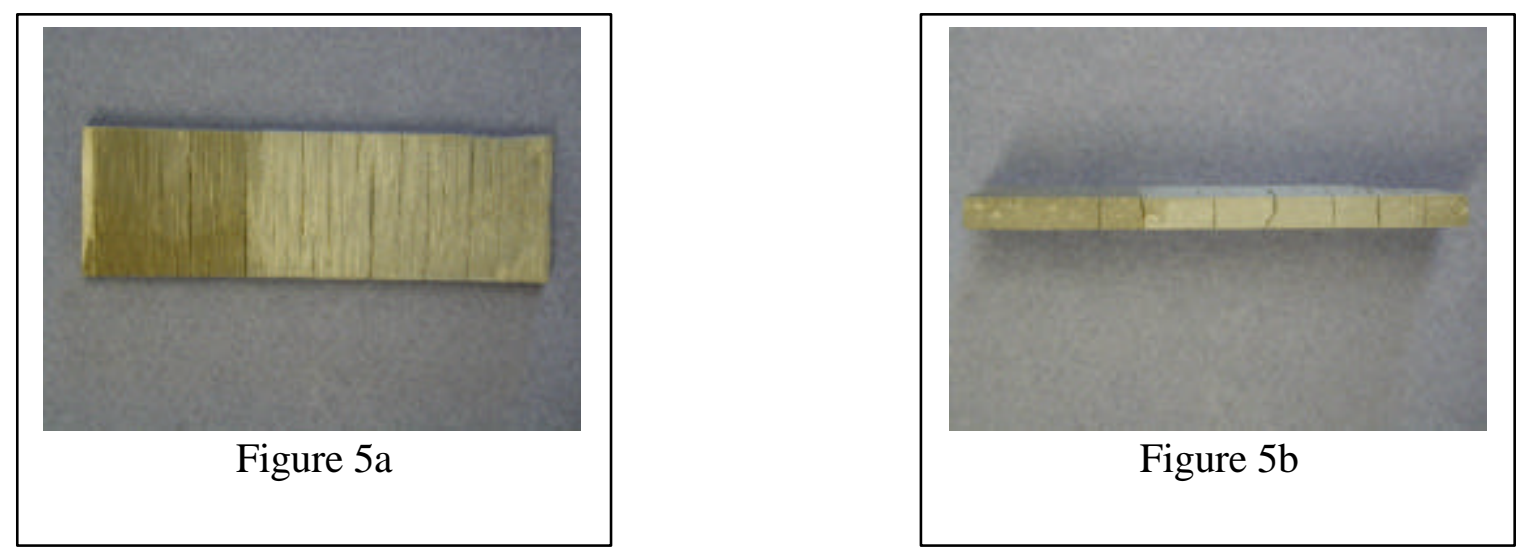

Figure $6 \mathrm{a}$ and $6 \mathrm{~b}$ show the result of confinement burnout of a button insert. No bloating, cracking and delaminating can be seen, very encouraging result.
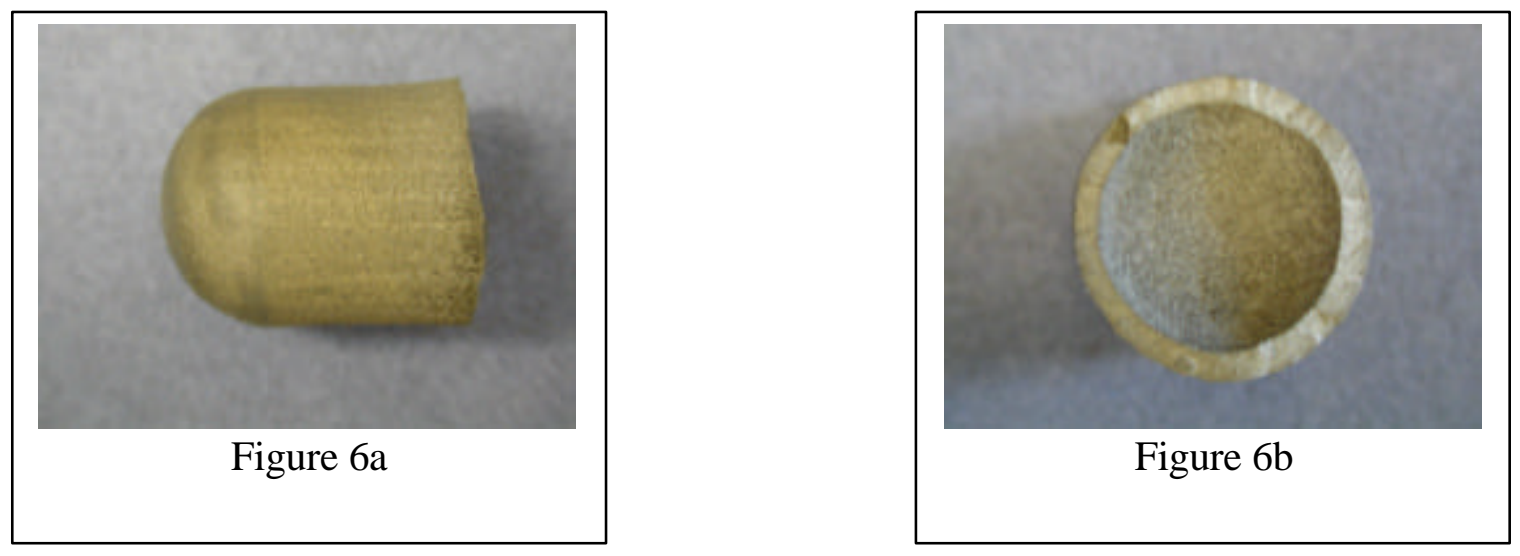

\section{$\underline{\text { Insert machining }}$}

Four FM button inserts were ground to the specified dimensions ( 0.905 " in height and 0.6895 " in diameter with a 60 deg tapered point). One of the resulting bit inserts has minor surface cracks, but is sufficient for field evaluation tests. This insert was produced by free standing burnout and sintering, followed by container HIPping. HIPping did not close all surface cracks generated during the free standing burnout. Figure $7 \mathrm{a}$ and $7 \mathrm{~b}$ are views of one of the machined inserts. The others appear unblemished and will be taken to Superior Rock Bit for placement on rock bits to evaluate insert performance under field drilling conditions. 

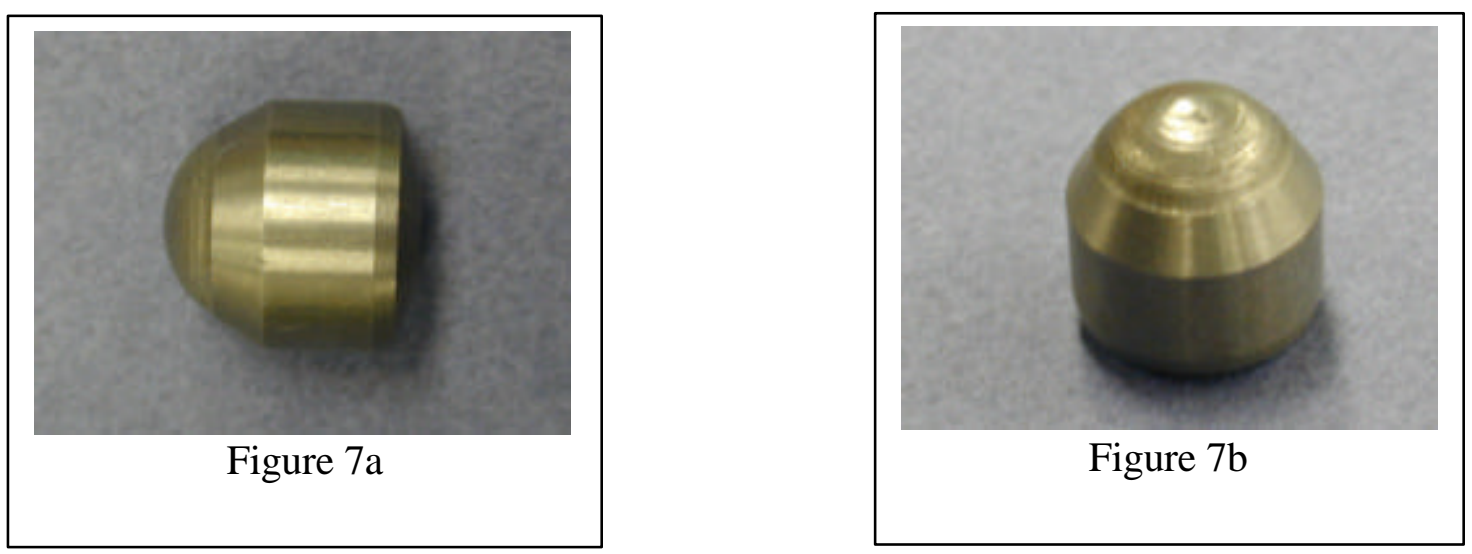

\section{Conclusions}

By the end of this quarter, a number of significant technical obstacles were addressed with positive results. Confinement of the FM piece during burnout proved to be the most successful process tested for reducing the occurrence of bloating, cracks, and delamination. Four rock bit inserts were machined from rods of FM material, and plans were made for field-testing next quarter. 